\title{
1,8-Bis(dimethylamino)naphthyl-2-ketimines: Inside vs outside protonation
}

\author{
A. S. Antonov ${ }^{* 1,2}$, A. F. Pozharskii ${ }^{1}$, P. M. Tolstoy ${ }^{2}$, A. Filarowski ${ }^{3,4}$ \\ and $\mathrm{O}$. V. Khoroshilova ${ }^{2}$
}

\section{Full Research Paper}

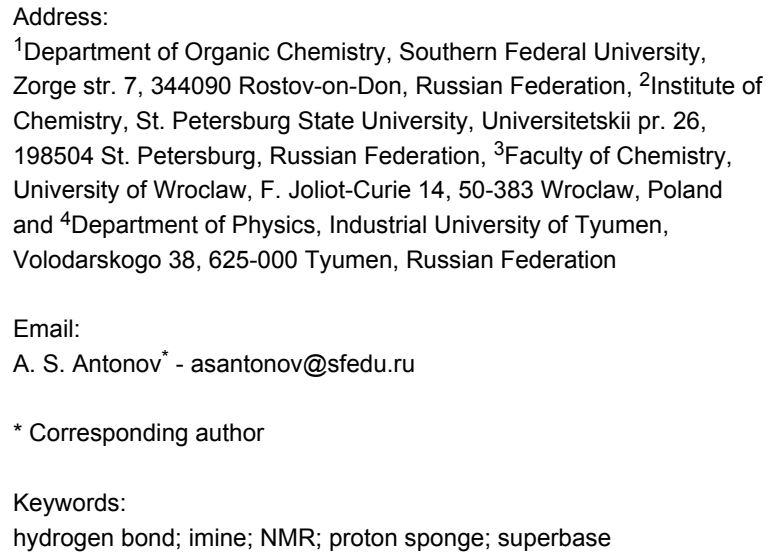
\author{
doi:10.3762/bjoc. 14.273 \\ Received: 19 September 2018 \\ Accepted: 15 November 2018 \\ Published: 28 November 2018 \\ Associate Editor: J. A. Murphy
}

Beilstein J. Org. Chem. 2018, 14, 2940-2948.

(C) 2018 Antonov et al.; licensee Beilstein-Institut. License and terms: see end of document.

\begin{abstract}
The structure and protonation behaviour of four ortho-arylketimines of 1,8-bis(dimethylamonio)naphthalene with a different number of methoxy groups in an aromatic substituent were investigated in solution by NMR (acetone, DMSO, MeCN), in solid state by $\mathrm{X}$-ray analysis and in the gas phase by DFT calculations. Both mono- and diprotonated species were considered. It has been shown that $E$-isomers of neutral imines can be stabilised by an intramolecular $\mathrm{C}=\mathrm{N}-\mathrm{H} \cdots \mathrm{OMe}$ hydrogen bond with a neighbouring methoxy group. Electron-donating OMe groups dramatically increase the basicity of the imino nitrogen, forcing the latter to abstract a proton from the proton sponge moiety in monoprotonated forms. The participation of the out-inverted and protonated $1-\mathrm{NMe}_{2}$ group in the $\mathrm{Me}_{2} \mathrm{~N}-\mathrm{H} \cdots \mathrm{NH}=\mathrm{C}$ hydrogen bond is experimentally demonstrated. It was shown that the number and position of OMe groups in the aromatic substituents strongly affects the rate of the internal hindered rotation of the $\mathrm{NH}_{2}^{+}$fragment in dications.
\end{abstract}

\section{Introduction}

It is well known that the extremely high basicity of 1,8 bis(dimethylamino)naphthalene (1, DMAN; $\mathrm{p} K_{\mathrm{a}}=12.1$ in $\mathrm{H}_{2} \mathrm{O}$ [1,2], 18.62 in MeCN [3], 7.5 in DMSO [4]) and its derivatives originates from the electrostatic repulsion between the unshared electron pairs of nitrogen atoms, which strongly destabilises the neutral base. This repulsion is additionally fortified by the steric inhibition of resonance (both $\mathrm{NMe}_{2}$ groups cannot be conjugated to the aromatic system at the same time) preventing charge delocalisation. The protonation results in the formation of the $\mathrm{N}-\mathrm{H} \cdots \mathrm{N}$ bonded cation $1 \mathrm{H}^{+}$, the removal of the electro- 
static and steric strain and thus a considerable free energy gain (Scheme 1) [5]. This is also a reason why the vast majority of DMAN derivatives are protonated to the internitrogen space, even if other centres of basicity are present in the molecule. The only exceptions are compounds $\mathbf{2}$ and $\mathbf{3}$ which are protonated to aza- and carbonyl groups, respectively (Scheme 2) [6]. This unusual protonation site originates from the conjugation between the $\mathrm{C}=\mathrm{N}(\mathrm{C}=\mathrm{O})$ and the $\mathrm{NMe}_{2}$ groups, leading to the formation of stabilised cations.

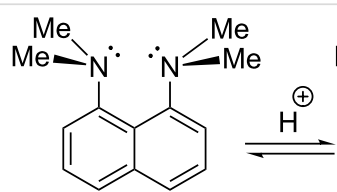

1<smiles>CN1[CH+]N(C)c2cccc3cccc1c23</smiles>

$1 \mathrm{H}^{+}$
Scheme 1: Protonation of DMAN.

In our recent work, we observed for the first time that the orthoketimino group in $\mathbf{4 a}$ can compete with the proton sponge moiety for the proton, which results in the formation of equilibria between the forms $\mathbf{4} \mathbf{b}$ (protonated to the proton sponge fragment) and $\mathbf{4} \mathbf{b}$ ' (protonated to the imino group) in the DMSO solution (Scheme 3) [7]. The aim of the present work is to investigate the major factors influencing the effective basicity of the imino functionality. As primary objects for this study, we consider a series of imines $\mathbf{4 a - 7 a}$ (Scheme 4), which differ by

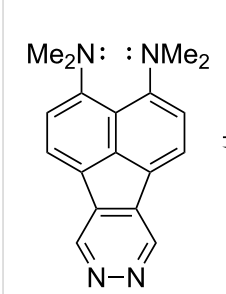

2<smiles>CC1=CC(=O)c2ccc(N(C)C)c3c(N(C)C)ccc1c23</smiles>

3

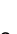
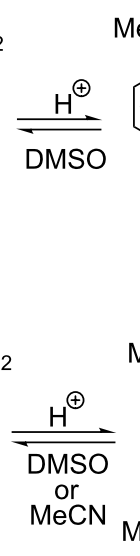

eCN

$\mathrm{Me}$

$3 \mathrm{H}^{+}$
Scheme 2: Protonation equilibria for 2 and 3.

the number and position of an OMe group in an aryl substituent. We hope that increasing the number of strong electron-donating groups will result in a significant transfer of basicity to the imino function. Selected series of neutral molecules $4 \mathbf{a}-7 \mathbf{a}$, as well as their mono- $(\mathbf{4 b}-\mathbf{7 b})$ and diprotonated $(\mathbf{4} \mathbf{c}-\mathbf{7} \mathbf{c})$ species were investigated by ${ }^{1} \mathrm{H}$ NMR spectroscopy in DMSO- $d_{6}$, $\mathrm{CD}_{3} \mathrm{CN}$ and acetone- $d_{6}$ in a wide range of temperatures. Results obtained in solutions were compared to single crystal X-ray structures and calculated equilibrium geometries of isolated molecules in a vacuum.

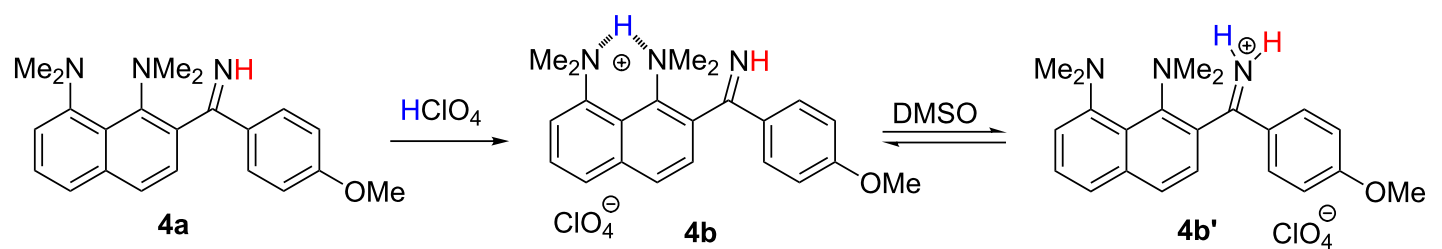

Scheme 3: Protonation of imine 4 a with perchloric acid.

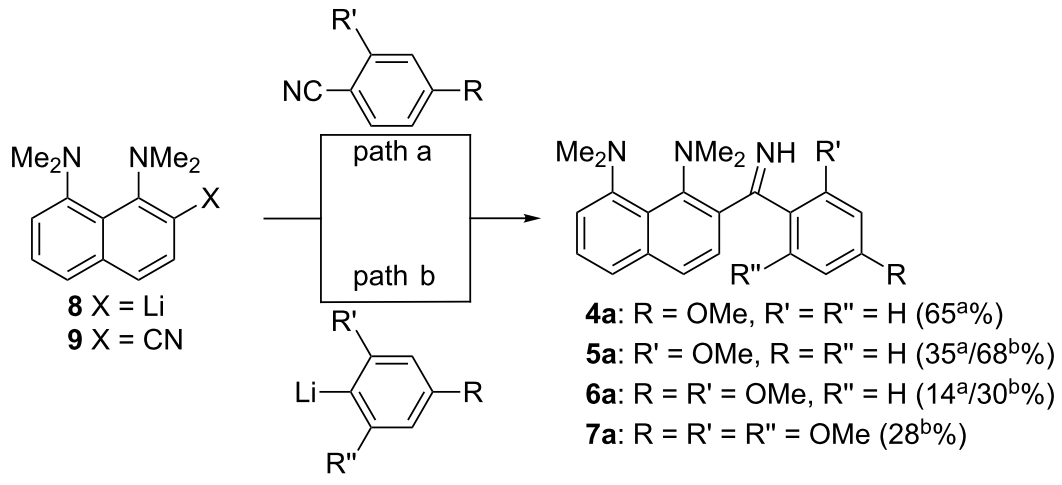

Scheme 4: Synthesis of investigated substrates (yields obtained by paths a and $\mathrm{b}$ are denoted by a corresponding superscript). 


\section{Results and Discussion}

\section{Synthesis of DMAN-ortho-ketimines and their cations}

Target compounds $\mathbf{4 a - 7 a}$ were synthesised by techniques previously developed in our laboratory (Scheme 4) [7,8]. Compounds $4 \mathbf{a}-6 \mathbf{a}$ were obtained by the treatment of the ortho-lithium derivative $\mathbf{8}$ with the corresponding nitrile (path a). Unfortunately, the strong election-donating effect of two and more OMe groups makes this approach not effective for the synthesis of compounds 6a and 7a. To overcome this difficulty, we used a reversed method based on the treatment of ortho-cyanide 9 with the corresponding aryllithiums, which produces the compounds 5a-7a with good to moderate yields (path b). The monocations $\mathbf{4 b}-\mathbf{7 b}$ and dications $\mathbf{4 c}-\mathbf{7} \mathbf{c}$ were prepared by the treatment of the corresponding imines with one or two equivalents of $\mathrm{HBF}_{4}$ in $\mathrm{Et}_{2} \mathrm{O}$ (Scheme 5). The so obtained tetrafluoroborates were used for NMR measurements after recrystallisation from EtOH.

\section{Structural investigations}

The structural investigations started with a ${ }^{1} \mathrm{H}$ NMR analysis of the imines $4 \mathbf{a}-7 \mathbf{a}$ in acetone- $d_{6}, \mathrm{CD}_{3} \mathrm{CN}$ and DMSO- $d_{6}$ in a wide range of temperatures. The main attention was paid to the chemical shift and the shape of the $\mathrm{C}=\mathrm{NH}$ and $\mathrm{NMe}_{2}$ groups' signals. Upon temperature decrease, the $\mathrm{NH}$ signal splits into two peaks of unequal intensity, which is best seen in the case of the acetone- $d_{6}$ solution (Figure 1). For example, for compound 4a, the $\mathrm{C}=\mathrm{NH}$ proton signals are at $\delta=9.9 \mathrm{ppm}$ and $10.7 \mathrm{ppm}$ at $-80^{\circ} \mathrm{C}$, with the major signal being in the higher field. In contrast, in the spectra of $\mathbf{5 a}-\mathbf{7} \mathbf{a}$, bearing OMe groups in orthoposition to the imino group, the major $\mathrm{NH}$ signal is located in the lower field (Figures S2-S4 in Supporting Information File 1). We assigned these signals to the $\mathrm{NH}^{\mathrm{a}}$ and $\mathrm{NH}^{\mathrm{b}}$ protons of $Z$ - and $E$-isomers, as shown in Scheme 6. We believe that in solution the $Z$-form is more stable for $\mathbf{4 a}$, while the $E$-form is more stable for $\mathbf{5 a}-\mathbf{7 a}$. Indeed, the $\mathrm{X}$-ray analysis shows that compound $\mathbf{6 a}$ in the solid state exists in the $E$-form stabilised by the $\mathrm{N}-\mathrm{H} \cdots \mathrm{O}$ intramolecular hydrogen bond (IHB) with an ortho-OMe group (Figure 2a), while compound $\mathbf{4 a}$, as it was revealed in our previous work [7], exists exclusively as a $Z$-isomer (Figure 2b). Moreover, gas phase quantum chemical calculations show that the $E$-form is preferable for $\mathbf{5 a}$ $\left(\Delta E=E_{Z}-E_{E}=1.66 \mathrm{kcal} / \mathrm{mol}\right), 6 \mathbf{6 a}(\Delta E=1.19 \mathrm{kcal} / \mathrm{mol})$, and $7 \mathbf{a}(\Delta E=1.90 \mathrm{kcal} / \mathrm{mol})$, while the $Z$-form dominates for $4 \mathbf{a}$ $(\Delta E=-2.62 \mathrm{kcal} / \mathrm{mol}$, Figure 3$)$. The contribution of the $\mathrm{N}-\mathrm{H} \cdots \mathrm{O}$ IHB to the stabilisation of the $E$-forms of $\mathbf{5 a - 7 a}$ appears to be small: in the ${ }^{1} \mathrm{H}$ NMR spectra, the $\mathrm{NH}^{\mathrm{a}}$ signal is shifted to the low field by less than $1 \mathrm{ppm}$ in comparison with Z-4a (Figure 1) [9]; in a DFT calculation, the mutual orientation of $\mathrm{C}=\mathrm{NH}$ and the OMe groups is not optimal for IHB formation.

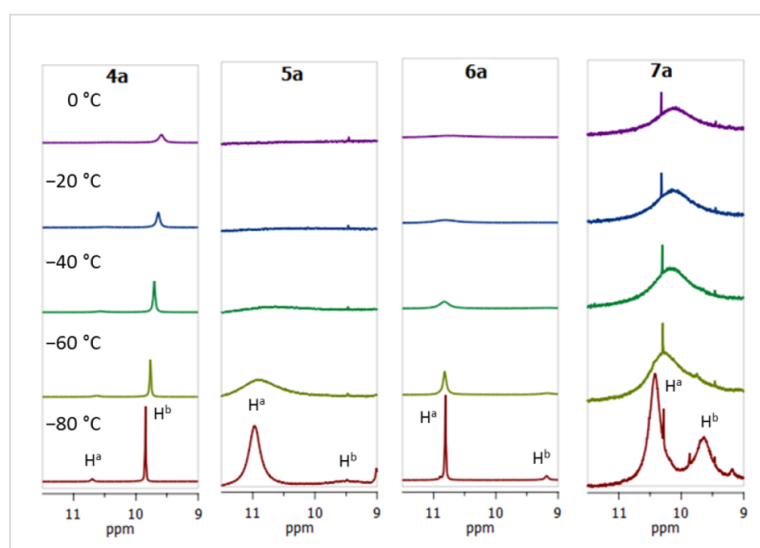

Figure 1: $\mathrm{C}=\mathrm{NH}$ Signal regions of temperature-depending ${ }^{1} \mathrm{H}$ NMR spectra for compounds $4 a-7 a$, acetone- $d_{6}$.

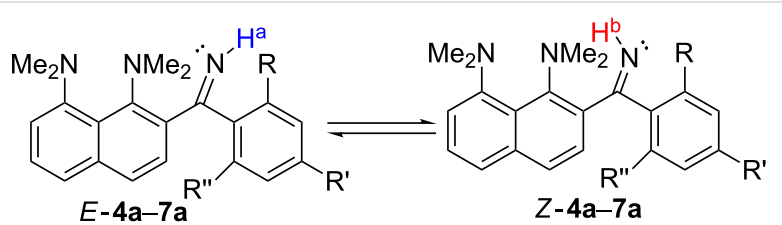

Scheme 6: E/Z-Isomerisation of ketimines $4 a-7 a$.

The rate and equilibrium constants of this uncatalysed isomerisation [10] depend on the solvent and temperature. By

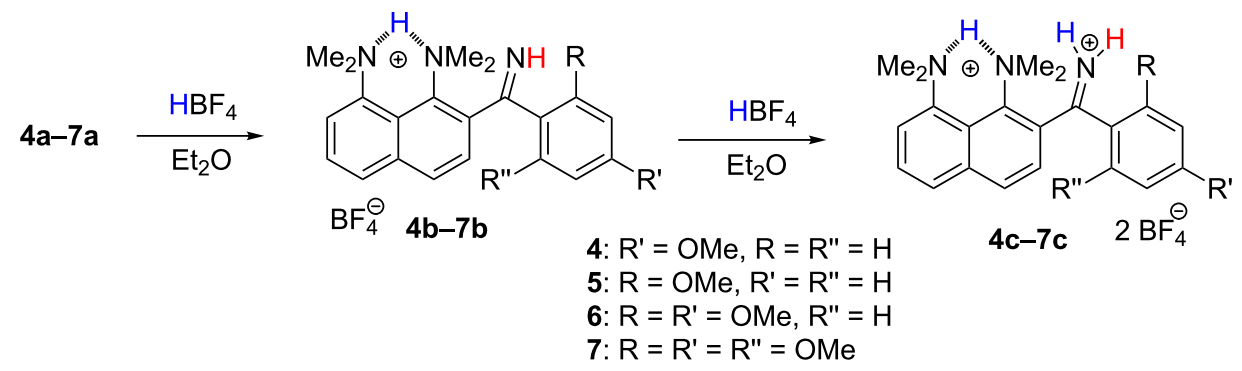




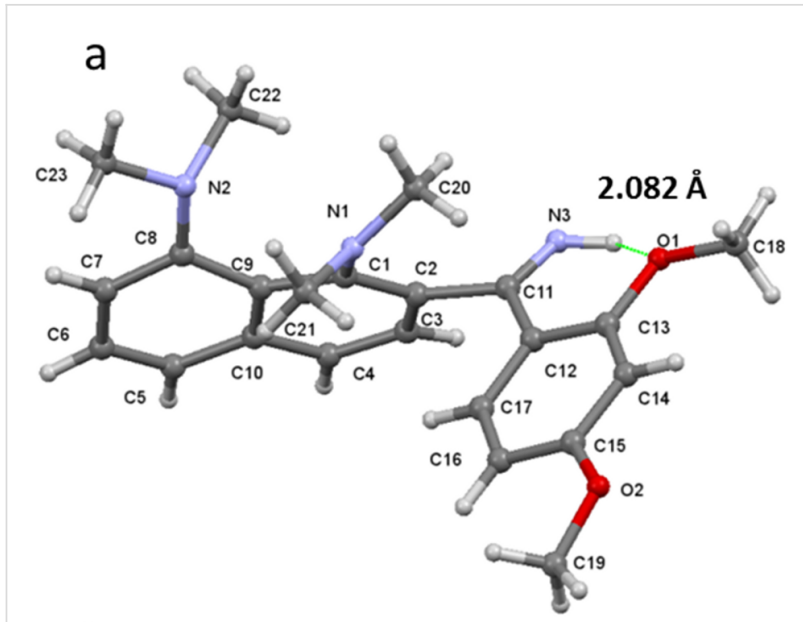

b

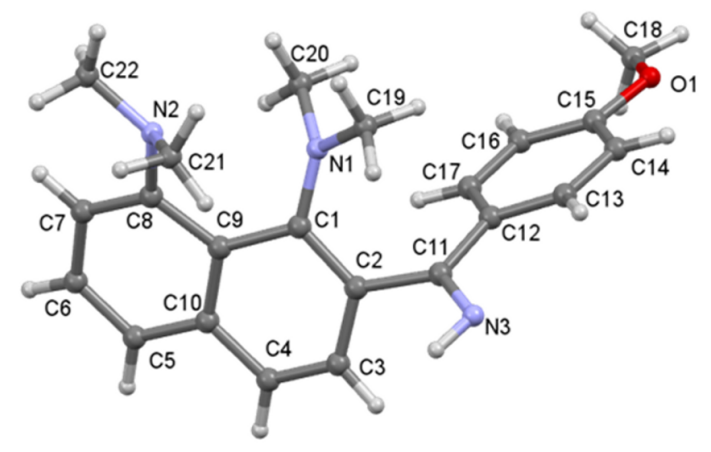

Figure 2: Molecular structure of imines $6 a(a)$ and $4 a(b)$. The $\mathrm{H} \cdots \mathrm{O}$ distance for $6 \mathbf{a}$ is shown.

comparing the results obtained in different solvents at equal temperatures, one can see that the $\mathrm{H}^{\mathrm{a}} \rightleftharpoons \mathrm{H}^{\mathrm{b}}$ exchange rate is noticeably lower in DMSO- $d_{6}$ (Figures S9-S12 in Supporting Information File 1) than in acetone- $d_{6}$ and $\mathrm{CD}_{3} \mathrm{CN}$ (Figures
S5-S8 in Supporting Information File 1), while the chemical shift differences between the $\mathrm{H}^{\mathrm{a}}$ and $\mathrm{H}^{\mathrm{b}}$ signals remain similar in all cases (ca. $1 \mathrm{ppm}$ ). The increased energy barrier for the isomerisation could be attributed to the stabilisation of the $Z$-form through formation of a stronger hydrogen bond between the DMSO molecule and the $\mathrm{NH}^{\mathrm{b}}$ proton [11], which is sterically unhindered and accessible for the solvent. Indeed, $\mathrm{X}$-ray data and quantum chemical calculations show that phenyl and naphthalene rings are almost perpendicular (Figure 2 and Figure 3).

After the first protonation of imines $4 \mathbf{a}-7 \mathbf{a}$ with $\mathrm{HBF}_{4}$, the ${ }^{1} \mathrm{H}$ NMR spectra display two sets of signals (Figure 4). One of the sets corresponds to the monocations $\mathbf{4 b}-\mathbf{7 b}$ protonated at the proton sponge site: the NHN bridging proton resonates at $\approx 19$ ppm and the positions of the $\mathrm{CH}$ signals of the dimethylaminonaphthalene fragment are typical and characteristic for protonated proton sponges [5]. In the other set of signals, the chemical shifts of the $\mathrm{NMe}_{2}$ groups are practically the same as for the neutral bases $4 \mathbf{a}-7 \mathbf{a}$. This means that protonation occurs at another basic site, which can only be imine nitrogen, i.e., the structure corresponds to monocations $\mathbf{4} \mathbf{b}^{\prime}-\mathbf{7 b}$ ' (Scheme 7). Indeed, around $10 \mathrm{ppm}$, a new signal appears which corresponds to two NH protons. To our knowledge, this is the first example of an imine to be basic enough to successfully compete for a proton with the proton sponge moiety: for example, the basicity of benzophenone imine $\left(\mathrm{p} K_{\mathrm{a}}=6.82\right)$ and even that of cyclohexanone imine $\left(\mathrm{p} K_{\mathrm{a}}=9.15\right)$ [12] is much lower than that of DMAN $\left(\mathrm{p} K_{\mathrm{a}}=12.1\right)[1,2]$. Moreover, as it was already mentioned in the introduction, this is the third known example of a DMAN derivative with a substituent that is more basic than the peri-dimethylaminonaphthalene core. Such an imine basicity boost can originate from the fact that upon protonation,

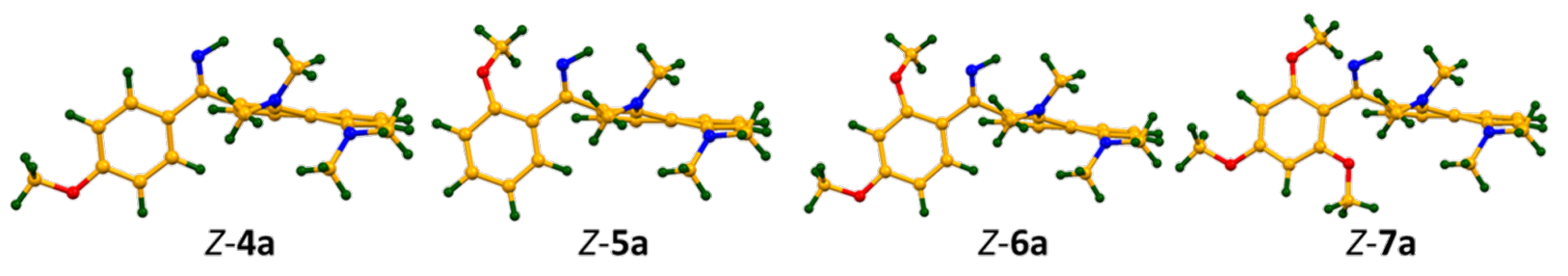

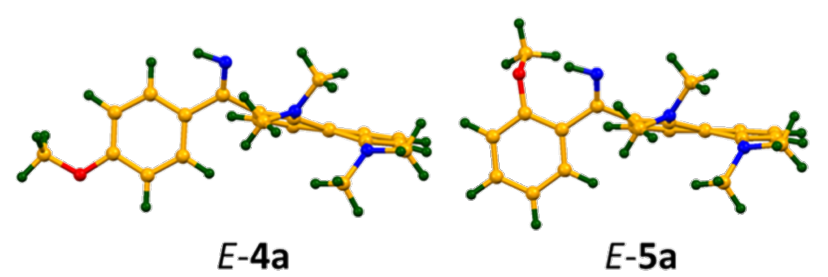

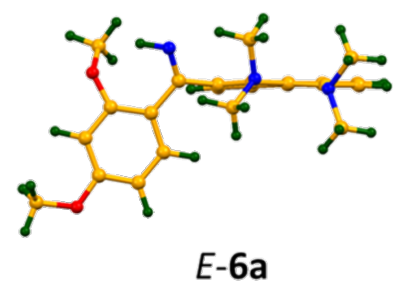

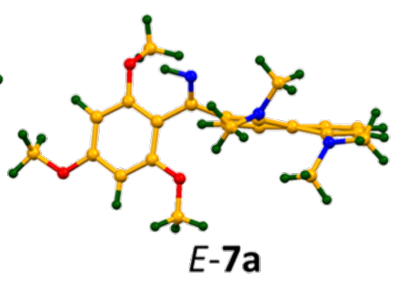

$\Delta E(\mathrm{kcal} / \mathrm{mol}): \quad+2.62$

$-1.66$

$-1.19$

$-1.90$

Figure 3: Optimised geometry and energy difference $\Delta E=E_{E}-E_{Z}(\mathrm{kcal} / \mathrm{mol})$ for imines 4a-7a $(\mathrm{B} 3 \mathrm{LYP} / 6-311+\mathrm{G}(\mathrm{d}, \mathrm{p}))$. 

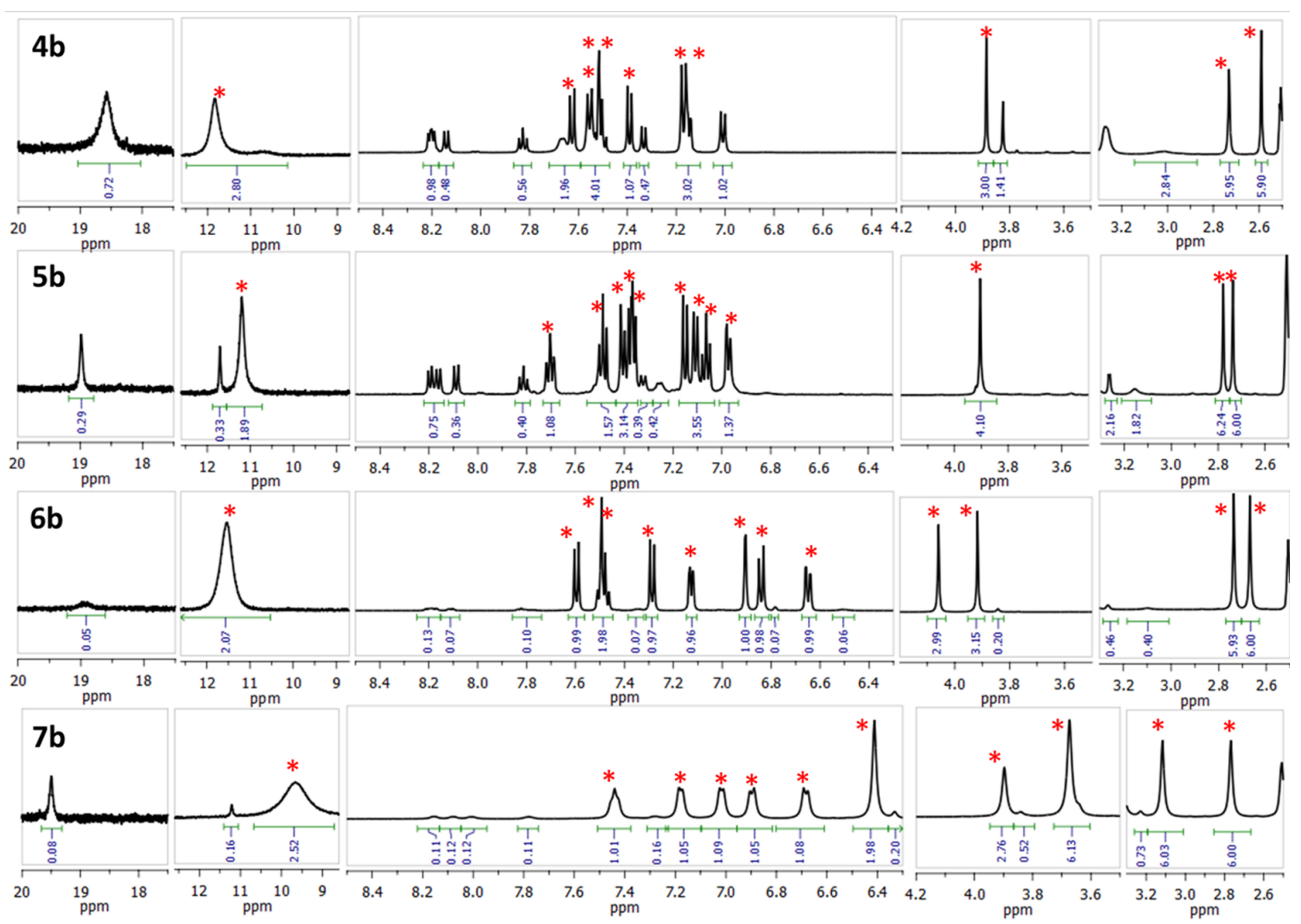

Figure 4: ${ }^{1} \mathrm{H}$ NMR spectra of imines $\mathbf{4 b}-\mathbf{7 b}\left(\mathbf{4} \mathbf{b}^{\prime}-\mathbf{7} \mathbf{b}^{\prime}\right)$ in DMSO- $d_{6}, 25^{\circ} \mathrm{C}$ (the signals of the forms protonated at the imino function are marked with an asterisk).

$\mathrm{NMe}_{2}$ groups lose conjugation with the ring whereas the $\mathrm{C}=\mathrm{N}$ moiety does not. As a result, the imino nitrogen saves the electron density supply from both $\mathrm{OMe}$ and $\mathrm{NMe}_{2}$ groups, which increases the s-character of nitrogen hybridisation thus fortifying the basicity [13].

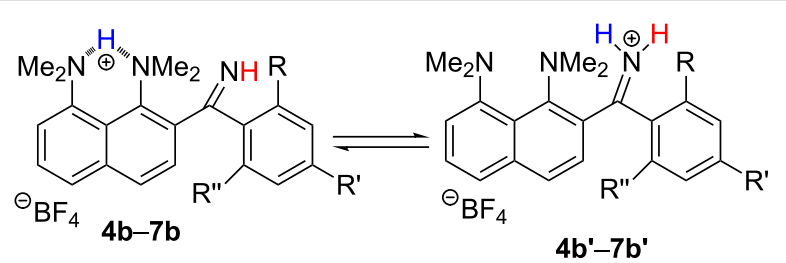

$$
\begin{aligned}
& \text { 4: } R^{\prime}=O M e, R=R^{\prime \prime}=H \\
& \text { 5: } R=O M e, R^{\prime}=R^{\prime \prime}=H \\
& \text { 6: } R=R^{\prime}=O M e, R^{\prime \prime}=H \\
& \text { 7: } R=R^{\prime}=R^{\prime \prime}=O M e
\end{aligned}
$$

Scheme 7: Switching of protonation sites in imines $\mathbf{4 b - 7 b}$.

The ratio of two monocations, estimated from ${ }^{1} \mathrm{H}$ NMR spectra at room temperature, depends on the position and number of the OMe groups and the solvent (Table 1; the values are practically temperature independent). One could expect that strong electron-donating OMe groups being placed in positions 2, 4 or 6 of a phenylimino substituent should increase the basicity of imine nitrogen. Thus, in $\mathrm{CD}_{3} \mathrm{CN}$, both $\mathbf{4 b}$ and $\mathbf{5 b}$, containing only one OMe group, show no proton transfer towards the imino function (Figure S13 in Supporting Information File 1). The addition of a second OMe group in the case of 6 leads to the formation of $25 \% \mathbf{6 b}$ '. Upon the insertion of a third OMe group in 7 , the amount of $\mathbf{7 b}$ ' expectedly increases to $33 \%$. Switching of the solvent to acetone- $d_{6}$ facilitates the proton transfer away from the proton sponge moiety (Figure S14, Supporting Infor-

Table 1: Influence of the solvent on the proton transfer to imino nitrogen in $\mathbf{4 b}-\mathbf{7 b}$ solutions at $25^{\circ} \mathrm{C}$.

solvent amount of protonated form, \%

\begin{tabular}{lllllllll} 
& $\mathbf{4 b}$ & $\mathbf{4 b}$ & $\mathbf{5 b}$ & $\mathbf{5 b}$ & $\mathbf{6 b}$ & $\mathbf{6 b}$ & $\mathbf{7 b}$ & $\mathbf{7 b}$ \\
\hline $\mathrm{CD}_{3} \mathrm{CN}$ & 100 & 0 & $>99$ & $<1$ & 75 & 25 & 70 & 30 \\
acetone $-d_{6}$ & $>99$ & $<1$ & 75 & 25 & 30 & 70 & 30 & 70 \\
DMSO- $_{6}$ & 30 & 70 & 30 & 70 & 10 & 90 & 10 & 90
\end{tabular}


mation File 1). For example, the relative amount of $\mathbf{7 b}$ ' increases from $33 \%$ to $66 \%$. Using DMSO- $d_{6}$ leads to the dramatic shift of the equilibrium, resulting in the formation of $90 \%$ 7b' (Figure 4). We believe that the forms protonated at the imino function are additionally stabilised by hydrogen bonds with solvent molecules and thus the amount of $\mathbf{b}$ ' forms correlates with the proton accepting ability of the medium [11]. The gas phase calculations show that without any additional interaction with the medium, the forms protonated at the imino group are lowest in energy for the imines 4, 6, 7 (Figure 5). In the solid state, no proton transfer to the imino group was observed: compounds $\mathbf{4} \mathbf{a} \cdot \mathrm{HClO}_{4}$ and $\mathbf{6} \mathbf{b} \cdot \mathrm{EtOH}$ crystallise in forms protonated at the proton sponge moiety (Figure 6).

We expected that the proton transfer to the $\mathrm{C}=\mathrm{N}$ group will force the nearest proton sponge moiety to occupy the in,outconformation [14] with the 1-NMe 2 group participating in $\mathrm{NHN}$ intramolecular hydrogen bonding with the $\mathrm{C}=\mathrm{NH}_{2}{ }^{+}$group (Scheme 8). Indeed, in the case of $\mathbf{7 b}$, which contains three OMe groups, we have found direct evidence of this process: the $1-\mathrm{NMe}_{2}$ group signal shifts from 2.8 to $3.3 \mathrm{ppm}$ - the characteristic region for protonated dimethylamino groups in proton sponges [5] - while the $8-\mathrm{NMe}_{2}$ group signals stay at $2.8 \mathrm{ppm}$. Thus, only the $1-\mathrm{NMe}_{2}$ group is protonated, which is only possible if it is out-inverted. Similar chemical shifts were observed for the cation 10 (Scheme 8, right), which is out-protonated due to steric reasons [15]. In refs. [15-17] it was shown that hydrogen bonding to an out-inverted $\mathrm{NMe}_{2}$ group without the proton transfer does not noticeably change the chemical shift of methyl protons. Thus, in the case of $\mathbf{7} \mathbf{b}^{\prime}$, the chemical shift at $3.3 \mathrm{ppm}$ proves the proton transfer to the amino nitrogen, as shown in Scheme 8 for (in,out)-7b'. In other words,
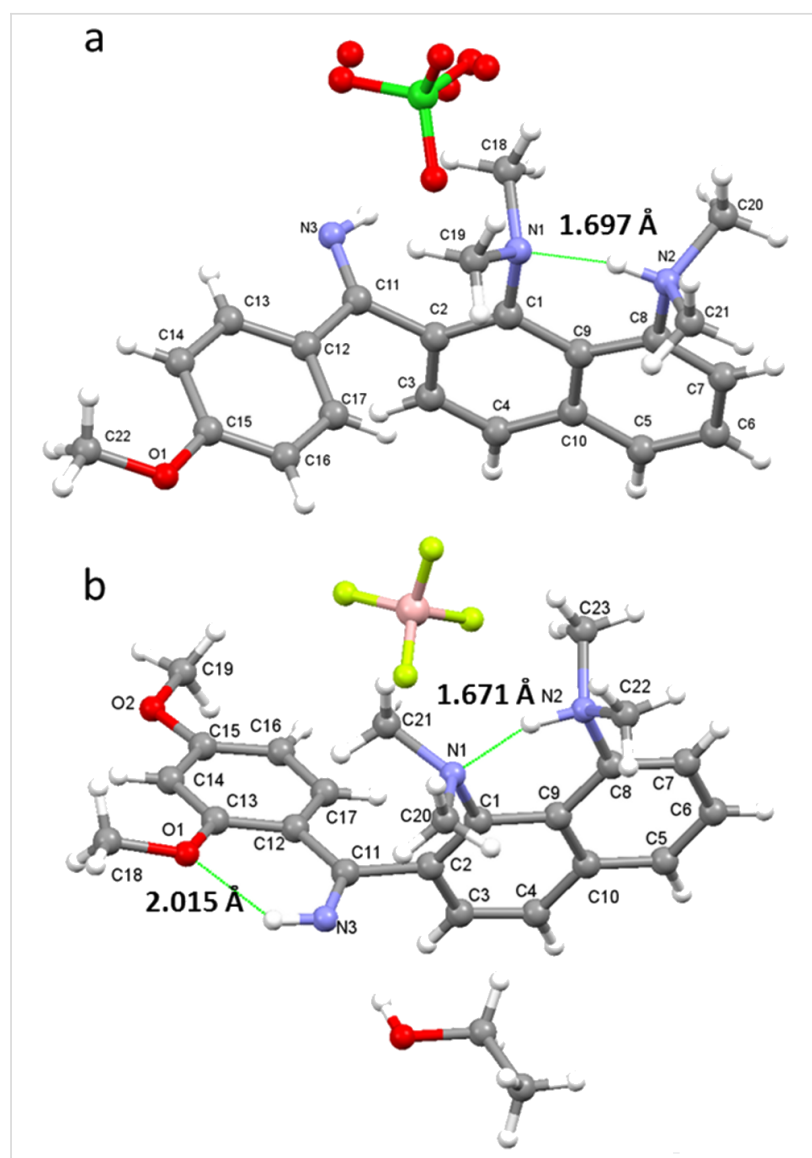

Figure 6: Molecular structure of protonated imines $4 a \cdot \mathrm{HClO}_{4}(\mathrm{a})$ and $6 \mathbf{b} \cdot \mathrm{EtOH}(\mathrm{b})$.

in the case of 7b', steric pressure of the trimethoxyphenyl substituent facilitates the $1-\mathrm{NMe}_{2}$ group's out-inversion which is stabilised by an IHB, forming $\mathrm{N}\left(\mathrm{sp}^{3}\right) / \mathrm{N}\left(\mathrm{sp}^{2}\right)$ type of proton

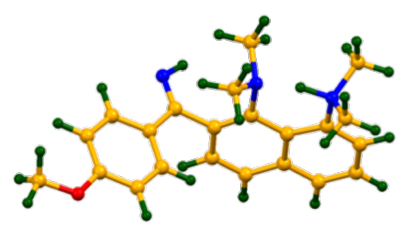

$Z-4 b$

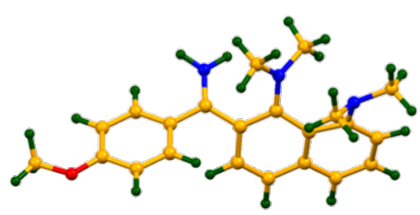

$4 b^{\prime}$

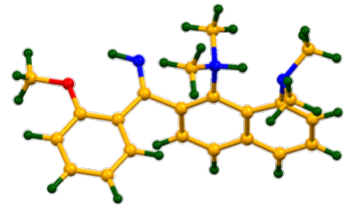

Z-5b

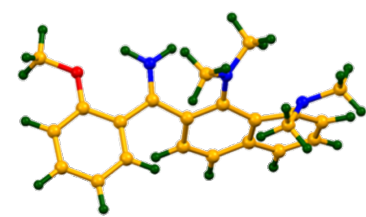

5b'

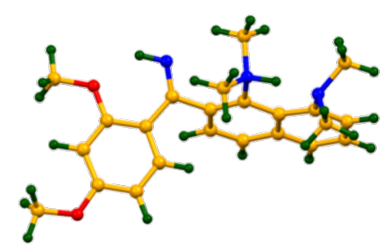

E-6b

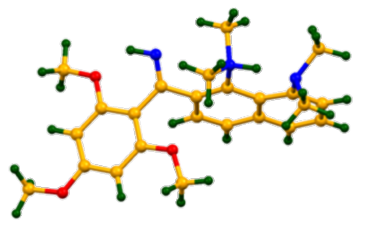

$E-7 \mathbf{b}$

$\Delta E(\mathrm{kcal} / \mathrm{mol}): \quad-2.32$

$+0.72$

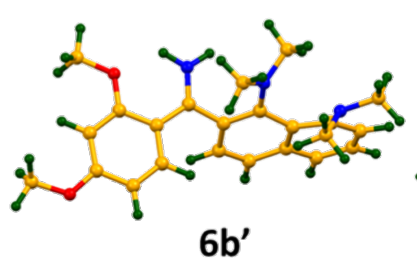

$-1.62$

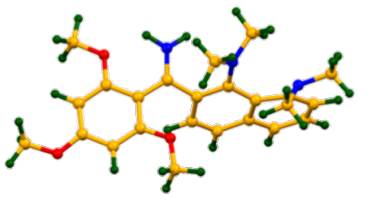

$7 b^{\prime}$

Figure 5: Optimised geometries and energy differences $\Delta E=E_{\mathrm{b}^{\prime}}-E_{\mathrm{b}}(\mathrm{kcal} / \mathrm{mol})$ for different sites of protonation of the studied imines (B3LYP/6$311+G(d, p))$. 

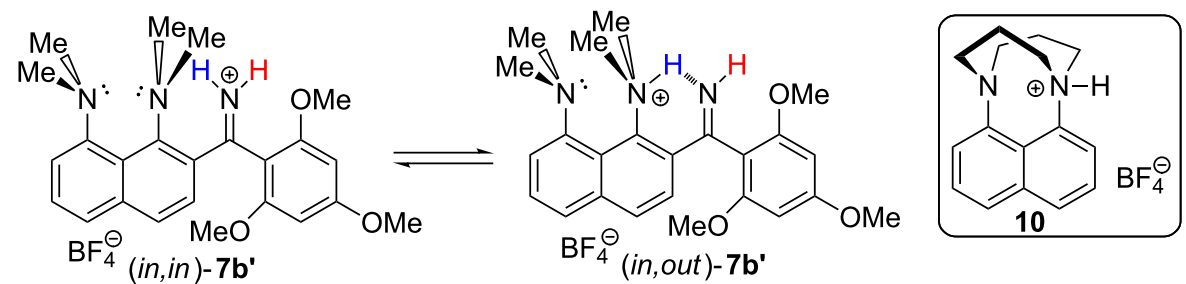

Scheme 8: Protonation of the out-inverted dialkylamino group

sponges, which were recently reported in our paper [18]. It was previously shown that the in,out-conformation can be stabilised by placing the following functionalities in position 2(7): tertiary alcoholic groups which are able to form the $\mathrm{O}-\mathrm{H} \cdots \mathrm{N}$ IHB $[16,17,19]$, bulky substituents rendering a steric pressure onto the $1-\mathrm{NMe}_{2}$ group $[7,20]$, or a metal atom coordinating the $\mathrm{NMe}_{2}$ group as a ligand causing its inversion [21] (Scheme 9). A possibility of out-protonation of 1,8-bis(dimethylamino)naphthalene was discussed in our recent paper [15], while it is experimentally demonstrated here for the first time.<smiles>[R]C1([R])O[CH][N+](C)(C)c2c1ccc1cccc([N+](C)(C)C)c21</smiles><smiles>C[N+](C)=Cc1c([Si](C)(C)C)ccc2ccc([Si](C)(C)C)c([N+](C)(C)C)c12</smiles>

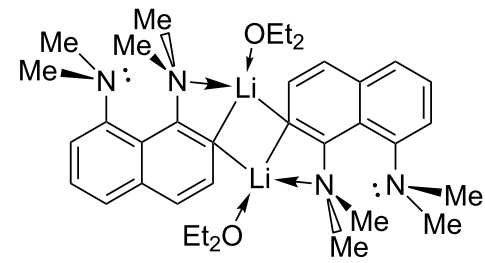

Scheme 9: Examples of proton sponges with stabilised in,out-conformation.

We also prepared dications $\mathbf{4 c - 7 c}$ (Scheme 5) and investigated their structure in solution in $\mathrm{CD}_{3} \mathrm{CN}$, DMSO- $d_{6}$ and acetone- $d_{6}$. It was found that the exchange rate between protons in the $\mathrm{C}=\mathrm{NH}_{2}{ }^{+}$group strongly depends on the position and number of OMe groups and the temperature. In the case of $\mathbf{4 c}$, signals are coalescent even at $-80{ }^{\circ} \mathrm{C}$ (Figure 7). The presence of an $\mathrm{OMe}$ group in the ortho-position to $\mathrm{C}=\mathrm{N}$ groups in $\mathbf{5 c}$ slows down the exchange and results in $\mathrm{NH}_{2}{ }^{+}$signals splitting at $-40{ }^{\circ} \mathrm{C}$. This can be attributed to the formation of the weak NHO intramolecular hydrogen bond, which becomes stronger upon inserting an additional OMe group. Such a NHO bond is clearly visible in the X-ray structure of $\mathbf{6 c}$ (Figure 8). As a result, in solutions of 6c and $7 \mathbf{c}, \mathrm{NH}_{2}{ }^{+}$proton signals are observed separately up to $40{ }^{\circ} \mathrm{C}$ (for spectra in $\mathrm{CD}_{3} \mathrm{CN}$ see also Figures S20-S23 in Supporting Information File 1).

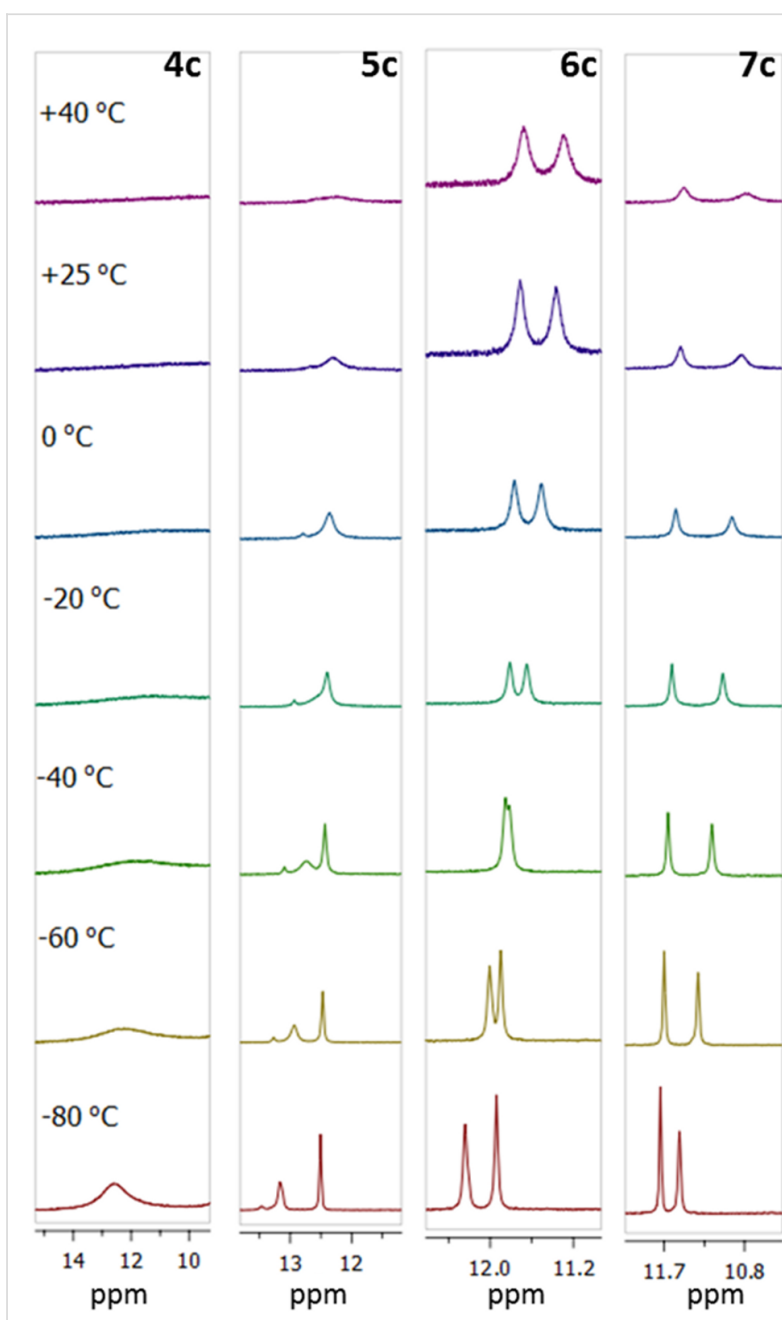

Figure 7: $\mathrm{C}=\mathrm{NH}_{2}{ }^{+}$Signal regions of temperature-depending spectra for compounds $4 c-7 c$, acetone- $d_{6}$.

\section{Conclusion}

In summary, we succeeded in preparing a new series of 1,8 bis(dimethylamino)naphthalene-ortho-ketimines with aromatic substituents containing strong electron donating OMe groups. Neutral compounds as well as their mono- and diprotonated species were studied. The obtained compounds demonstrated increased basicity of the imino nitrogen, which was able to effectively compete for the proton with the proton sponge core. 


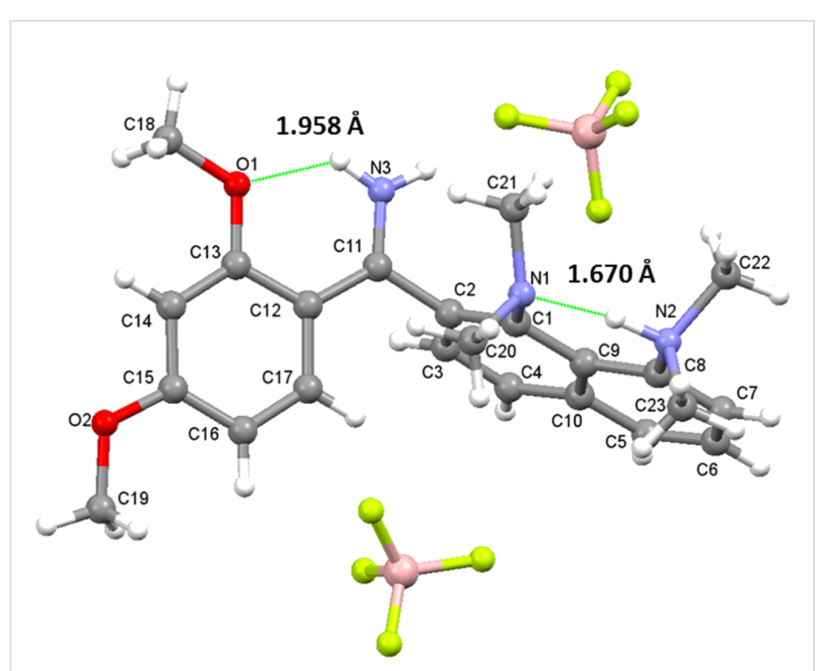

Figure 8: Molecular structure of dication 6c.

Increasing the number of OMe groups facilitated the proton transfer to the imino function by up to $90 \%$. As a result, studied compounds can be considered as superbasic imines. In one case, we were able to experimentally observe the simultaneous outinversion and protonation of the $1-\mathrm{NMe}_{2}$ group for the first time.

\section{Supporting Information}

\section{Supporting Information File 1}

Experimental procedures and analytical data, copies of ${ }^{1} \mathrm{H}$ NMR spectra of all studied compounds, ${ }^{1} \mathrm{H}$ and

${ }^{13} \mathrm{C}$ NMR spectra confirming the structure of new compounds, crystallographic data for $\mathbf{6 a}, \mathbf{6 b}, \mathbf{6 c}$ and $\mathbf{4 a} \cdot \mathrm{HClO}_{4}$.

[https://www.beilstein-journals.org/bjoc/content/ supplementary/1860-5397-14-273-S1.pdf]

\section{Supporting Information File 2}

CIF file for compound $\mathbf{6 a}-\mathbf{c}$ and $\mathbf{4 a} \cdot \mathrm{HClO}_{4}(\mathrm{CCDC}$ 1867639-1867642).

[https://www.beilstein-journals.org/bjoc/content/ supplementary/1860-5397-14-273-S2.cif]

\section{Acknowledgements}

This work was supported by the Russian Foundation for Basic Research (project 16-33-60030). Experimental measurements were performed in Centre for Magnetic Resonance, Chemical Analysis and Materials Research Centre, Centre for X-ray Diffraction Studies at St. Petersburg State University Research Park. The authors also thank Mr. Daniel Raith for proofreading the paper in terms of the English language.

\section{ORCID ${ }^{\circledR}$ iDs}

A. S. Antonov - https://orcid.org/0000-0001-7047-789X

P. M. Tolstoy - https://orcid.org/0000-0002-8426-3988

A. Filarowski - https://orcid.org/0000-0003-1013-4945

O. V. Khoroshilova - https://orcid.org/0000-0002-3502-4403

\section{References}

1. Alder, R. W.; Bowman, P. S.; Steele, W. R. S.; Winterman, D. R. Chem. Commun. 1968, 723-724. doi:10.1039/c19680000723

2. Hibbert, F. J. Chem. Soc., Perkin Trans. 21974, 1862-1866. doi:10.1039/p29740001862

3. Kaljurand, I.; Kütt, A.; Sooväli, L.; Rodima, T.; Mäemets, V.; Leito, I.; Koppel, I. A. J. Org. Chem. 2005, 70, 1019-1028. doi:10.1021/jo048252w

4. Benoit, R. L.; Lefebvre, D.; Fréchette, M. Can. J. Chem. 1987, 65, 996-1001. doi:10.1139/v87-170

5. Pozharskii, A. F.; Ozeryanskii, V. A. Proton Sponges. In The Chemistry of Anilines; Rappoport, Z., Ed.; John Wiley \& Sons, Ltd: Chichester, UK, 2007; pp 931-1026. doi:10.1002/9780470871737.ch17

6. Pozharskii, A. F.; Ozeryanskii, V. A.; Vistorobskii, N. V. Russ. Chem. Bull. 2003, 52, 218-227. doi:10.1023/a:1022429322461

7. Antonov, A. S.; Mikshiev, V. Y.; Pozharskii, A. F.; Ozeryanskii, V. A. Synthesis 2014, 46, 3273-3282. doi:10.1055/s-0034-1379008

8. Povalyakhina, M. A.; Antonov, A. S.; Dyablo, O. V.; Ozeryanskii, V. A.; Pozharskii, A. F. J. Org. Chem. 2011, 76, 7157-7166. doi:10.1021/jo201171z

9. Afonin, A. V.; Vashchenko, A. V.; Sigalov, M. V. Org. Biomol. Chem. 2016, 14, 11199-11211. doi:10.1039/c6ob01604a

10. Curtin, D. Y.; Grubbs, E. J.; McCarty, C. G. J. Am. Chem. Soc. 1966 88, 2775-2786. doi:10.1021/ja00964a029

11. Laurence, C.; Graton, J.; Berthelot, M.; Besseau, F.; Le Questel, J.-Y.; Luçon, M.; Ouvrard, C.; Planchat, A.; Renault, E. J. Org. Chem. 2010, 75, 4105-4123. doi:10.1021/jo100461z

12. Albert, A.; Serjeant, E. P. The lonization Constants of Typical Acids and Bases. The Determination of lonization Constants; Springer Netherlands: Dordrecht, 1984; pp 136-175. doi:10.1007/978-94-009-5548-6_9

13. Alabugin, I. V.; Bresch, S.; dos Passos Gomes, G. J. Phys. Org. Chem. 2015, 28, 147-162. doi:10.1002/poc.3382

14. Szemik-Hojniak, A.; Zwier, J. M.; Buma, W. J.; Bursi, R.; van der Waals, J. H. J. Am. Chem. Soc. 1998, 120, 4840-4844. doi:10.1021/ja974245w

15. Ozeryanskii, V. A.; Pozharskii, A. F.; Antonov, A. S.; Filarowski, A. Org. Biomol. Chem. 2014, 12, 2360-2369. doi:10.1039/c3ob41986j

16. Pozharskii, A. F.; Degtyarev, A. V.; Ryabtsova, O. V.; Ozeryanskii, V. A.; Kletskii, M. E.; Starikova, Z. A.; Sobczyk, L.; Filarowski, A. J. Org. Chem. 2007, 72, 3006-3019. doi:10.1021/jo062667v

17. Pozharskii, A. F.; Degtyarev, A. V.; Ozeryanskii, V. A.; Ryabtsova, O. V.; Starikova, Z. A.; Borodkin, G. S. J. Org. Chem. 2010, 75, 4706-4715. doi:10.1021/jo100384s

18. Pozharskii, A. F.; Ozeryanskii, V. A.; Mikshiev, V. Y.; Antonov, A. S.; Chernyshev, A. V.; Metelitsa, A. V.; Borodkin, G. S.; Fedik, N. S.; Dyablo, O. V. J. Org. Chem. 2016, 81, 5574-5587. doi:10.1021/acs.joc.6b00917 
19. Pozharskii, A. F.; Ryabtsova, O. V.; Ozeryanskii, V. A.;

Degtyarev, A. V.; Starikova, Z. A.; Sobczyk, L.; Filarowski, A.

Tetrahedron Lett. 2005, 46, 3973-3976.

doi:10.1016/j.tetlet.2005.04.045

20. Pozharskii, A. F.; Ryabtsova, O. V.; Ozeryanskii, V. A.;

Degtyarev, A. V.; Kazheva, O. N.; Alexandrov, G. G.; Dyachenko, O. A.

J. Org. Chem. 2003, 68, 10109-10122. doi:10.1021/jo035350t

21. Antonov, A. S.; Pozharskii, A. F.; Ozeryanskii, V. A.; Filarowski, A.;

Suponitsky, K. Y.; Tolstoy, P. M.; Vovk, M. A. Dalton Trans. 2015, 44

17756-17766. doi:10.1039/c5dt02482j

\section{License and Terms}

This is an Open Access article under the terms of the Creative Commons Attribution License

(http://creativecommons.org/licenses/by/4.0). Please note that the reuse, redistribution and reproduction in particular requires that the authors and source are credited.

The license is subject to the Beilstein Journal of Organic

Chemistry terms and conditions:

(https://www.beilstein-journals.org/bjoc)

The definitive version of this article is the electronic one which can be found at: doi:10.3762/bjoc. 14.273 